\title{
Estudo etiológico e epidemiológico da "doença da vaca caída"
}

\section{Etiological and epidemiological study of the bovine paraplegic disease}

Estudio de la etiología y epidemiología de la enfermedad de la "vaca caída"

\section{Aulus Cavalieri Carciofi'; Luís Carlos Marques²; Flávio Prada ${ }^{3}$; Ruben Pablo Schocken-Iturrino4; Antônio Carlos Alessi ${ }^{5}$}

Departamento de Clínica e Cirurgia Veterinária da Faculdade de Ciências Agrárias e Veterinárias da Universidade do Estadual Paulista, UNESP, Campus de Jaboticabal. Jaboticabal, SP, Brasil. 


\section{Resumo}

Objetivo: Investigar a etiologia e o panorama epidemiológico da "doença da vaca caída" em bovinos atendidos no Hospital Veterinário "Governador Laudo Natel" da Faculdade de Ciências Agrárias e Veterinárias da Universidade Estadual Paulista (FCAV/UNESP), Campus de Jaboticabal, Jaboticabal, SP. Material e Método: Procedeu-se ao exame clínico, avaliação neurológica, colheita de soro sangüíneo e líquido rumenal para a detecção de toxina botulínica, líquido cefalorraquidiano para diagnóstico de encefalites, exame necroscópico, exame histopatológico do cérebro e o diagnóstico de raiva. Caracterizou-se o manejo, tipo de exploração zootécnica, nutrição, sanidade e colheu-se dados epidemiológicos dos surtos. Resultados: Foram incluídas 24 fazendas e 29 animais. O inquérito epidemiológico totalizou 7.261 bovinos, sendo 143 doentes gerando uma taxa de morbidade geral de $2 \%$ (2,6\% dentre novilhas, $2,2 \%$ dentre vacas, $1,7 \%$ dentre garrotes e $0,6 \%$ dentre bois), $40 \%$ dos animais acometidos foram garrotes, seguidos pelas vacas $(28 \%)$ e novilhas $(27 \%)$. A taxa de morbidade variou entre propriedades $(0,14 \%$ a $57,5 \%)$ com letalidade próxima à $100 \%$. Empregavam sal comum misturado ao sal mineral $57 \%$ das propriedades e $30 \%$ destas sal mineral completo comercial, a quantidade fornecida foi considerada inadequada em 54\%. Predominaram pastos de Braquiaria $s p$ em manejo extensivo sem adubação. Apenas dois proprietários referiram osteofagia, apesar de $45 \%$ dos pastos apresentarem ossadas. Os bovinos apresentaram-se em decúbito externo-abdominal ou lateral, 40\% com diminuição do tônus da língua e $80 \%$ com diminuição do tônus e ausência de movimentos de cauda. Dentre os diagnósticos que puderam ser firmados verificou-se as seguintes freqüências de ocorrência: 3,4\% de polioencefalomalácia; 3,4\% de raiva; $10,3 \%$ de encefalite; $3,4 \%$ de falência de órgãos; $41,4 \%$ de botulismo; $38,1 \%$ idiopáticos, pois os animais não apresentaram sinais ou alterações que permitissem um diagnóstico conclusivo. Conclusões: Conclui-se que se trata de doença de etiologia multifatorial e cujo panorama epidemiológico necessita de investigações mais abrangentes, a fim de se estabelecer métodos de controle mais eficientes.

Palavras-chave: Botulismo. Clostridium botulinum. Toxina botulínica tipo A. Paraplegia, epidemiologia. Paraplegia, etiologia. Pastagens. Brachiaria. Bovinos de corte.

\section{Introdução e Revisão de Literatura}

A paraplegia dos membros pélvicos dos bovinos, conhecida como "doença da vaca caída”, é uma doença endêmica de muitas regiões do Brasil e que têm ocasionado sérios prejuízos à pecuária nacional. Apesar de inexistirem dados oficiais, acredita-se que entre as décadas de 70 e 90 tenham morrido, vitimadas pela doença, mais de um milhão e duzentas mil cabeças de gado, particulamente bovinos de corte (LISBÔA ${ }^{1}$, 1994).

De etiologia ainda controversa, sabe-se que a intoxicação botulinica constitui-se em uma das causas da doença (DUTRA $\left.{ }^{2}, 1991\right)$, sendo ainda consideradas a subnutrição (OLIVEIRA ${ }^{3}$, 1993), deficiências minerais e intoxicação por flúor $\left(\mathrm{LEMOS}^{4}, 1989\right)$ ou mesmo a ocorrência de entidades mórbidas distintas, que teriam um diagnóstico clínico e epidemiológico semelhantes (ORTOLANI $\left.{ }^{5}, 1993\right)$. O último autor coloca que a doença correlaciona-se com um tripé de condições: criação de bovinos em solos de baixa fertilidade, pastagens formadas por capins do gênero Braquiaria e falhas no manejo dos rebanhos, com destaque para a má suplementação mineral. Muitos autores consideram, também, como ocorrência concomitante e fator predisponente, a deficiência de fósforo nos animais acometidos (TOKARNIA et al. ${ }^{6}, 1988$; DUTRA ${ }^{2}, 1991$; DUTRA; DOBEREINER ${ }^{7}, 1995$; LISBÔA et al. ${ }^{8}, 1996$ ).

No Brasil, a "paraplegia dos membros pélvicos", "doença da vaca caída", ou "doènça da mão dura" foi 
em camundongos, segundo recomendações do Centers for Disease Control and Prevention ${ }^{18}$ (1998).

\section{Análise Estatística dos Dados}

Para a análise estatistica dos dados estes foram classificados qualitativamente em positivo ou negativo para as variáveis botulismo, postura (decúbito externoabdominal ou lateral), visão (presente ou ausente), audição, contagem de células no líqüor (normal ou aumentada), quantidade de sal (suficiente ou insuficiente) e tipo de cocho (coberto ou descoberto) e em positivo, intermediário ou negativo para as variáveis estado mental (alerta, apático ou deprimido), tônus da língua (normal, diminuído ou ausente), sensibilidade paravertebral e dos membros, movimentos de cauda (normal, induzido ou ausente), tipo de pasto - predominantemente Brachiaria decumbens (B. decumbens), Brachiaria brizantha (B. brizantha) ou Panicum maximo (P. maximo), e tipo de sal - comercial completo, mistura preparada na propriedade ou com proteínas.

Os dados assim organizados foram submetidos ao Teste Exato de Fischer para a verificação da associação de duas variáveis e ao Teste de Correlação de Spearmen, considerando-se como significante $\mathrm{p}<0,05$. A análise foi conduzida no software estatístico SAS ${ }^{\text {- }}$ System for elementary statistical analysis ${ }^{19}$. cria $(23 \%)$, cinco à cria, recria e engorda (23\%), duas à recria e engorda (9\%) e quatro à engorda de bovinos (18\%). Em relação aos animais que participaram do estudo epidemiológico, o número total de bovinos somou 7.261, sendo 2.054 vacas, 1.115 novilhas, 96 touros, 1.626 garrotes, 1.094 bezerros e 1.259 bois.

Quanto ao tipo de gramínea, a grande maioria das propriedades eram formadas por Brachiaria sp, sendo a maioria delas pela espécie $B$. brizantha, como pode ser visto na Figura 1. Muitas fazendas apresentam mais de um tipo de gramínea. Verificou-se, também, variação na taxa de lotação animal por hectare, encontrando-se lotações de um animal por ha em $28 \%$ das fazendas, dois animais por ha em $24 \%$ das propriedades e três animais por ha em $18 \%$ das propriedades.As fazendas caracterizam-se, ainda, por realizar manejo extensivo das pastagens $(81 \%)$, que em sua grande maioria não são adubadas (86\%). Ainda quanto à alimentação, $86 \%$ delas não fornecem nenhum tipo de suplemento alimentar, além do sal mineral. O fornecimento de água aos animais era realizado, em $58 \%$ das propriedades por meio de aguadas naturais e $42 \%$ por bebedouros artificiais, apresentando algumas propriedades os dois tipos de aguada. Destas, $35 \%$ foram consideradas inadequadas por apresentarem, segundo as respostas ao questionário, sujeira, lodo, restos de fezes, carcaças de animais e contaminação com água pluvial de estradas.

Em relação ao manejo sanitário, 10,5\% das propriedades vermifugavam os animais uma vez ao ano, $53 \%$ duas vezes por ano, $26,3 \%$ três vezes e $10,5 \%$

\section{Estudo Epidemiológico}

Foram incluídas 24 fazendas e 29 animais. Das fazendas que participaram do estudo, uma destina-se à produção leiteira e 23 à produção de gado de corte. Quanto ao tipo de manejo, 22 foram classificadas como de manejo extensivo, uma semi-intensivo e uma como de manejo intensivo. Dentre as fazendas de corte, forma de exploração zootécnica especialmente acometida pela doença, seis destinavam-se à cria $(27 \%)$, cinco à cria e re-

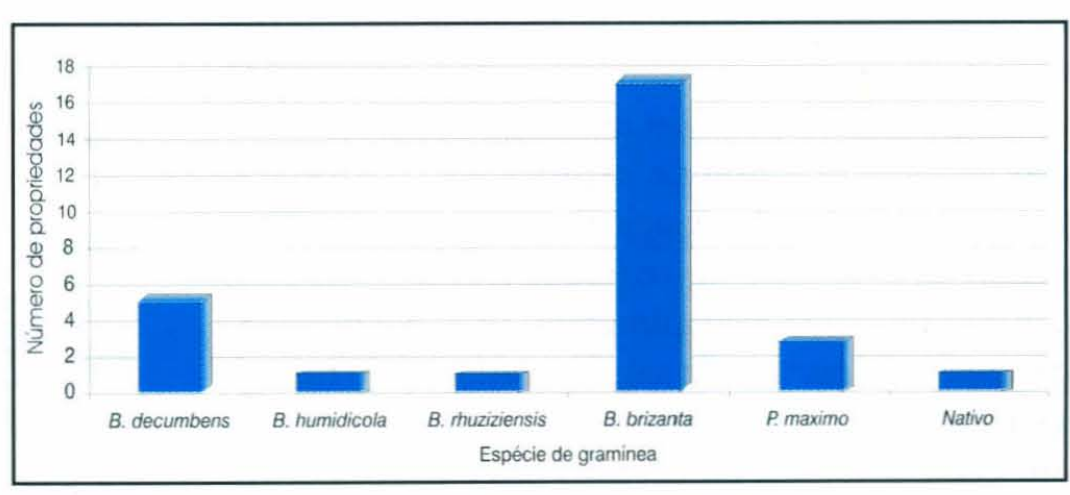

Figura 1 - Espécies de gramíneas utilizadas nas pastagens de 24 fazendas cujos rebanhos apresentaram a "doença da vaca caída" 


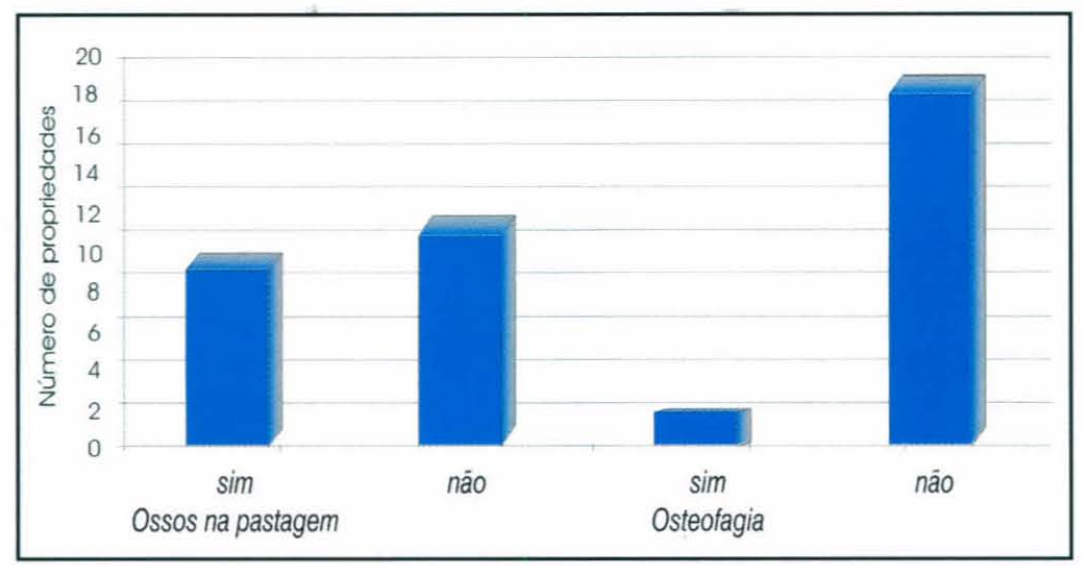

Figura 2 - Presença de ossadas nas pastagens e de osteofagia nos animais de 24 fazendas cujos rebanhos apresentaram a "doença da vaca caída"

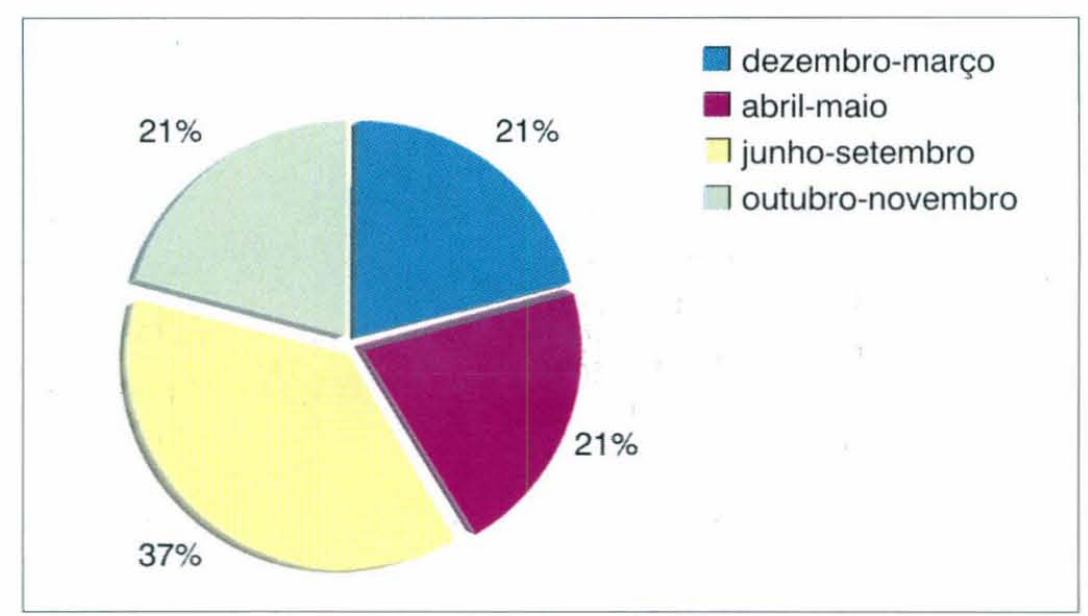

Figura 3 - Distribuição percentual da época do ano de ocorrência da "doença da vaca caída" em 24 fazendas estudadas

quatro vezes ao ano. Dentre as vacinas empregadas a totalidade das propriedades relatou a imunização contra febre aftosa, 15 contra carbúnculo hemático e sintomático, cinco contra toxina botulínica, dois contra o vírus rábico e apenas um para brucelose.

Devido à estreita relação apregoada entre o botulismo e à osteofagia avaliou-se o relato da ocorrência de ossadas na pastagem e de osteofagia em animais do rebanho. Quanto à presença de ossadas, 10 fazendas relatam sua presença e 13 fazendas afirmam que todas as carcaças são removidas e enterradas. A osteofagia foi relatada em apenas duas propriedades avaliadas (Figura 2).
A casuística de animais atendidos com a "Síndrome da Vaca Caída" no HVGLN não seguiu um padrão estacional como descrito na literatura. No presente estudo o ano foi dividido em quatro períodos, início das chuvas (outubro e novembro), período chuvoso (dezembro a março), início das secas (abril a maio) e período seco (junho a setembro). Foram atendidos cinco animais no período chuvoso, cinco animais no início da seca, nove animais no período seco e cinco animais no início das chuvas, demonstrando um padrão constante de ocorrência ao longo do ano (Figura 3).

Durante o estudo, somou-se um total de 143 animais acometidos. Estes dividiram-se em 57 garrotes, 


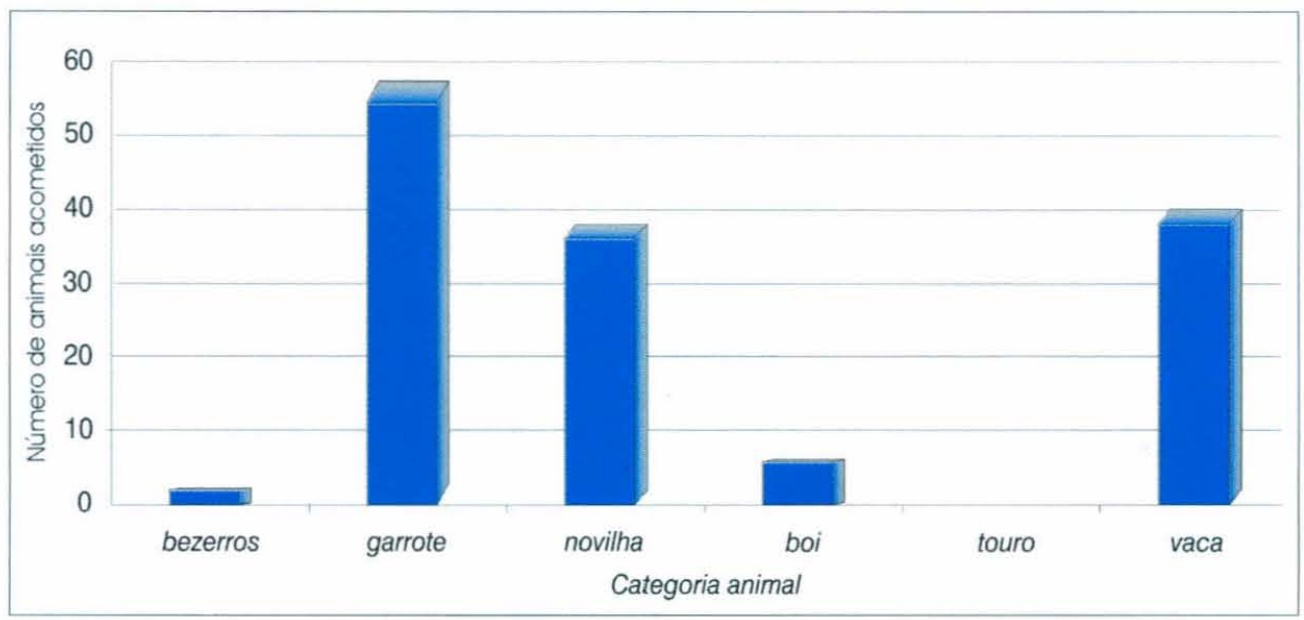

Figura 4 - Número de animais acometidos pela "doença da vaca caída” segundo o sexo e faixa etária, de 24 fazendas estudadas

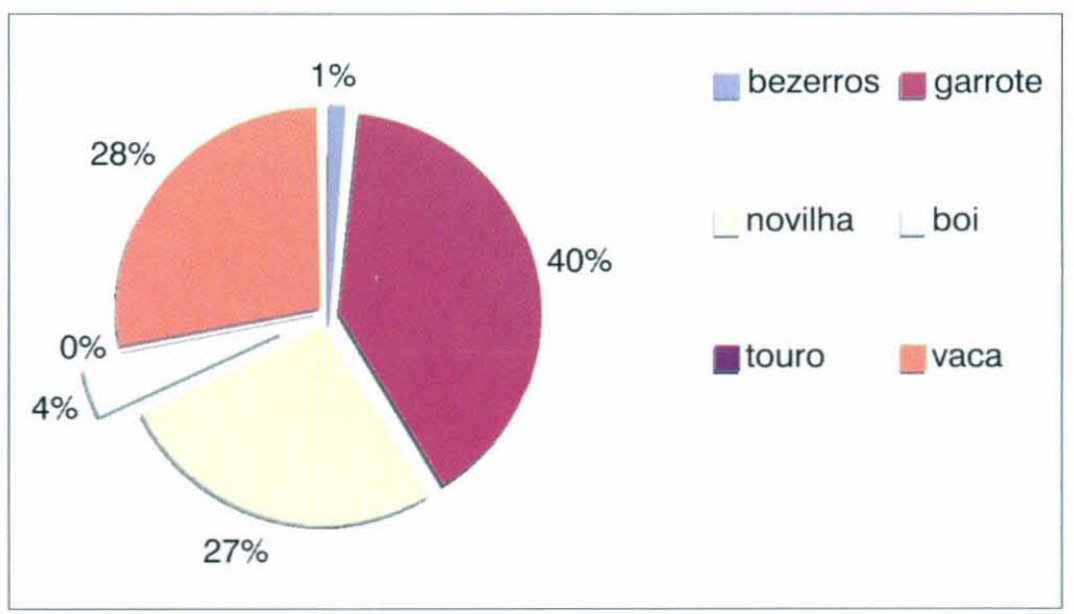

Figura 5 - Distribuição percentual dos animais acometidos pela "doença da vaca caída”, em relação ao total de animais doentes, de 22 fazendas estudadas

38 novilhas, seis bois e 40 vacas (Figura 4), gerando uma taxa de morbidade total (número de doentes em relação ao total de animais) de $2 \%$. A Taxa de Morbidade Proporcional, que se refere ao número de doentes em relação do total de animais de sua categoria e idade, resultou em $1,7 \%$ para garrotes, $2,6 \%$ para novilhas, $0,6 \%$ para bois e $2,2 \%$ para vacas, apontando maior morbidade entre novilhas, e não em vacas como normalmente descrito. Entretanto, considerando-se a porcentagem de ocorrência entre os animais doentes, tem-se que os garrotes foram os mais freqüentemente acometidos, com 57 animais vitimados no período, seguidos pelas vacas com 40 , novilhas com 38 , bois com seis e bezerros com dois animais doentes, como pode ser visualizado na Figura 5.

Em relação ao estágio fisiológico das vacas acometidas, 29 eram lactentes ( $72 \%)$, oito secas e gestantes $(20 \%)$ e três lactentes e gestantes $(8 \%)$. Nenhuma vaca seca não gestante foi acometida pela doença. Entre um e 20 bovinos, com média de seis animais, foram acometidos por surto/fazenda. Dentro de uma mesma fazenda a taxa de morbidade variou de $0,14 \%$ a $57,5 \%$, caracterizando uma doença com grande impacto econômico potencial em algumas propriedades. A taxa de mortalidade foi muito próxima à de morbidade, com poucos animais recuperando-se 
Tabela 1 - Taxas de morbidade, mortalidade e letalidade de 21 propriedades que apresentaram surto epizoótico da "doença da vaca caída"

\begin{tabular}{|c|c|c|c|}
\hline Propriedade & $\begin{array}{c}\text { Taxa de } \\
\text { morbidade }\end{array}$ & $\begin{array}{c}\text { Taxa de } \\
\text { mortalidade }\end{array}$ & $\begin{array}{l}\text { Taxa de } \\
\text { letalidade }\end{array}$ \\
\hline 1 & $10,0 \%$ & $10,0 \%$ & $100 \%$ \\
\hline 2 & $1,7 \%$ & $1,7 \%$ & $100 \%$ \\
\hline 3 & $0,9 \%$ & $0,9 \%$ & $100 \%$ \\
\hline 4 & $2,5 \%$ & $2,5 \%$ & $100 \%$ \\
\hline 5 & $3,6 \%$ & $1,8 \%$ & $50,0 \%$ \\
\hline 6 & $18,5 \%$ & $18,5 \%$ & $100 \%$ \\
\hline 7 & $9,1 \%$ & $9,1 \%$ & $100 \%$ \\
\hline 8 & $0,14 \%$ & $0,14 \%$ & $100 \%$ \\
\hline 9 & $1,0 \%$ & $1,0 \%$ & $100 \%$ \\
\hline 10 & $3,7 \%$ & $3,7 \%$ & $100 \%$ \\
\hline 11 & $5,0 \%$ & $4,0 \%$ & $80,0 \%$ \\
\hline 12 & $1,3 \%$ & $1,3 \%$ & $100 \%$ \\
\hline 13 & $1,0 \%$ & $1,0 \%$ & $100 \%$ \\
\hline 14 & $1,0 \%$ & $1,0 \%$ & $100 \%$ \\
\hline 15 & $16,9 \%$ & $16,9 \%$ & $100 \%$ \\
\hline 16 & $57,5 \%$ & $55,0 \%$ & $95,7 \%$ \\
\hline 17 & $8,0 \%$ & $6,6 \%$ & $66,6 \%$ \\
\hline 18 & $0,6 \%$ & $0,6 \%$ & $100 \%$ \\
\hline 19 & $0,2 \%$ & $0,2 \%$ & $100 \%$ \\
\hline 20 & $7,5 \%$ & $5,3 \%$ & $66,6 \%$ \\
\hline 21 & $12,0 \%$ & $8,3 \%$ & $70,0 \%$ \\
\hline
\end{tabular}

da afecção, o que redundou em taxa de letalidade de $90 \%$. Uma descrição das taxas de morbidade, mortalidade e letalidade de 21 das propriedades estudadas encontra-se na Tabela 1.

\section{Estudo Clínico}

Dos 29 bovinos que participaram do estudo, sete apresentavam-se hipotérmicos no momento do primeiro exame clínico, estando os demais com temperatura corpórea normal. Em relação à inspeção de mucosas, 11 apresentavam congestão, um icterícia e os demais mucosas róseas. Quanto ao grau de hidratação, 11 apresentavam exicose leve, quatro exicose moderada, dois exicose severa e os demais hidratação normal. À avaliação clínica os demais parâmetros pesquisados encontraram-se dentro da normalidade considerada para a espécie bovina.

A avaliação neurológica dos bovinos atendidos incluiu as determinações do estado mental, postura corporal, capacidades visual e auditiva, tônus da língua, movimentos de cauda, reflexo anal e sensibilidade cutânea paravertebral e nos membros torácicos e pélvicos. Sugerindo condição mais grave, 15 bovinos apresentavam-se em decúbito lateral e 14 em decúbito externo-abdominal. Classificados quanto ao estado mental em apáticos, deprimidos e alertas, sete animais mostraram-se apáticos, oito deprimidos e 14 mantinham-se alertas. A função visual foi considerada ausente (cegueira aparente) em apenas três animais, nos quais posteriormente diagnosticou-se polioencefalomalacia, meningoencefalite ou quadro clínico e anatomopatológico compatível com febre catarral maligna. A audição foi considerada presente em todos os bovinos, com exceção de um animal, que também não apresentava visão, no qual foi diagnosticado meningoencefalite. Em relação à musculatura da língua, 11 animais apresentavam tônus diminuído, uma única vaca apresentou protrusão lingual e os restantes 17 animais tônus normal.

Os movimentos de cauda foram classificados como espontâneos, induzidos (quando o animal só movimentava a cauda quando estimulado) ou ausentes. Em 17 bovinos verificou-se ausência de movimentos de 


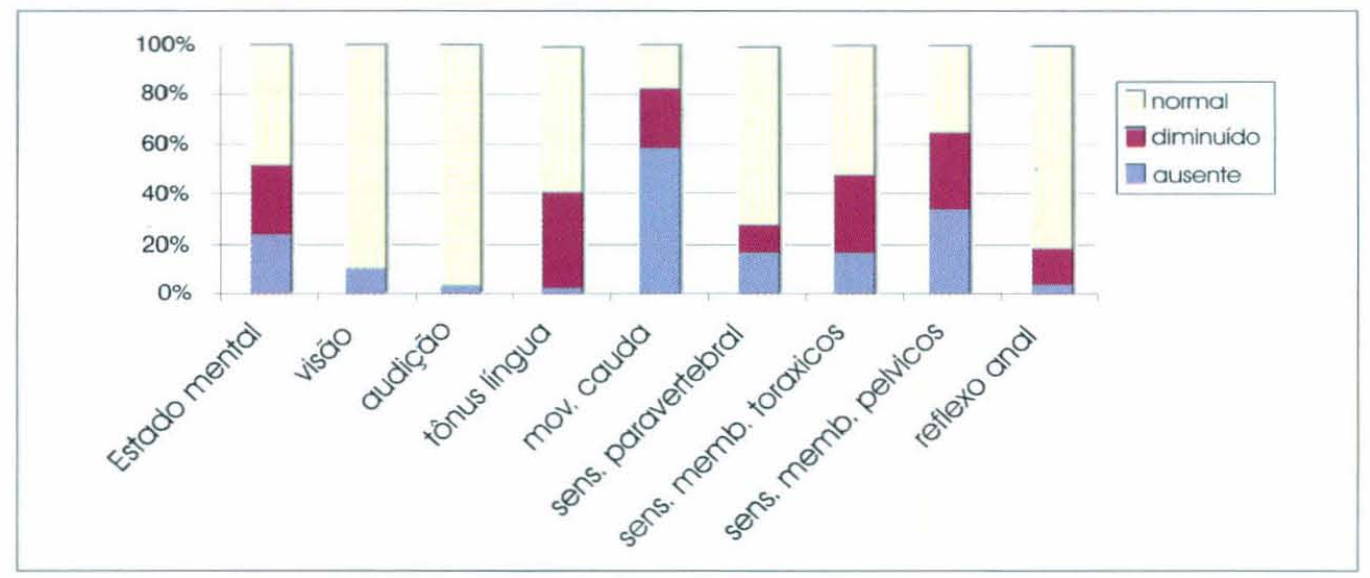

Figura 6 - Representação gráfica, em porcentagem, dos dados clínicos referentes ao exame neurológico de 29 bovinos com paraplegia dos membros posteriores atendidos no Hospital Veterinário "Governador Laudo Natel" da FCAV/UNESP, Jaboticabal, SP

cauda, com esta apresentando paralisia flácida, outros sete apresentaram comprometimento de motilidade, com apenas movimentos induzidos, e os demais movimentos espontâneos. O reflexo anal não foi normal em $76 \%$ dos bovinos, diminuído em $19 \%$ e ausente em $5 \%$.

Na avaliação da sensibilidade cutânea 18 bovinos apresentaram sensibilidade cutânea paravertebral normal, três sensibilidade diminuída e cinco ausente. A sensibilidade cutânea nos membros torácicos foi classificada como normal em 12 animais, diminuída em nove e ausente em outros cinco bovinos. Por fim, a sensibilidade cutânea dos membros pélvicos apresentou-se normal em 10 animais, diminuída em oito e ausente em outros oito bovinos.

O exame de líqüor revelou elevada contagem de céluas, cuja média foi de $61,9 \mathrm{~mL}$.

Uma tentativa de sistematizar os dados clínicos referentes ao exame neurológico dos bovinos atendidos encontra-se na Figura 6. Nesta os parâmetros estão ilustrados em porcentagem de ocorrência dentre as categorias normal, diminuído e ausente.

\section{Exame Necroscópico e Histopatológico}

Aos exames necroscópico e histopatológico, oito animais apresentaram enterite catarro-hemorrágica, cinco não apresentaram alterações, dois alterações moderadas em pulmões, em um animal diagnosticouse polioencefalomalacia, em outro diagnosticou-se raiva, um apresentava sinais de falência orgânica generalizada induzida por nefrite intersticial crônica, um demonstrou lesões necroscópicas e histopatológicas compatíveis com febre catarral maligna, dois bovinos apresentaram encefalite não supurada, dois apenas alterações hepáticas discretas, em outros três animais não foi possível realizar-se necrópsia e três recuperaramse e tiveram alta hospitalar. Em nenhum bovino encontrou-se vacuolização neuronal ou de neurópilo. Apesar da minuciosa busca no trato digestório de ossos deglutidos, decorrente de uma possível osteofagia, estes não foram localizados em nenhum dos bovinos necropsiados.

\section{Detecção de Toxina Botulínica}

A análise laboratorial para a detecção de intoxicação botulínica apontou como positivos, confirmando, portanto, a intoxicação botulínica como a causa da sintomatologia observada, $41,4 \%$ dos casos.

\section{Análise Estatística}

O Teste Exato de Fischer e a Correlação de Spearman foram empregado para verificar, respectivamente, associação e correlação entre o diagnóstico 
Tabela 2 - Etiologias e respectivas freqüências de ocorrência da "doença da vaca caída" (síndrome paraplégica dos bovinos) em 29 animais atendidos no Hospital Veterinário Governador Laudo Natel da FCAV-UNESP, Jaboticabal, SP

\begin{tabular}{lc}
\hline Etiologia & $\begin{array}{c}\text { Frequiência } \\
\text { de ocorrência }\end{array}$ \\
\hline Polioencefalomalacea & $3,4 \%$ \\
Raiva & $3,4 \%$ \\
Encefalite & $10,3 \%$ \\
Falência orgânica & $3,4 \%$ \\
Botulismo & $41,4 \%$ \\
\hline Idiopática & $38,1 \%$ \\
\hline
\end{tabular}

laboratorial de botulismo e todas as variáveis epidemiológicas, clínicas e anatomopatológicas pesquisadas. O diagnóstico de botulismo não apresentou associação ou correlação com nenhuma das variáveis comparadas.

\section{Estudo Etiológico}

Os resultados do exame clínico, de líquor, anatomopatológico e da detecção de toxina botulínica permitiram firmar o diagnóstico em apenas $61,9 \%$ dos bovinos atendidos. Estes resultados estão compilados na Tabela 2 .

\section{Discussão}

O estudo epidemiológico demonstrou que algumas variáveis pesquisadas resultaram em índices semelhantes aos descritos na literatura, outras, no entanto, divergiram. Nas propriedades que acorreram ao HVFCAV/UNESP para diagnóstico e orientação uma porcentagem maior de explorações dedicadas à recria $\mathrm{e}$ engorda foi detectada. Assim, o número de machos envolvidos no estudo foi relativamente grande. Talvez devido a isto, a incidência da doença em machos foi alta, os garrotes foram a categoria animal mais acome- tida, representando quase $40 \%$ das mortes. As vacas ficaram em segundo lugar e as novilhas em terceiro. Computando a proporção de doentes entre machos e fêmeas, teve-se $44 \%$ e $56 \%$, respectivamente. Estes dados não corroboram com Pinheiro, et al. ${ }^{9}$ (1984) que encontraram incidência de $81,6 \%$ em fêmeas e $18,4 \%$ em machos.

Isto ilustra algumas distorções que ocorreram no estabelecimento da morbidade, principalmente a morbidade proporcional da doença. Langenegger e Dobereiner $^{20}$ (1980), Pinheiro, et al. ${ }^{9}$ (1984), Dobereiner, et al. ${ }^{15}$ (1990), Dutra²(1991), Ortolani $^{5}(1993)$ e Lisbôa et al. ${ }^{1}$ (1994) afirmam que a mortalidade acomete principalmente vacas, no entanto os rebanhos de corte, principalmente no Brasil central onde a doença foi mais extensamente estudada, destinam-se basicamente a cria e cria e recria, com poucas propriedades realizando engorda de animais. Nestas condições a proporção de vacas no rebanho é muito alta, novilhas e garrotes aparecem em segundo lugar, os bois são mantidos apenas nas fazendas de engorda e os touros, devido à larga relação entre machos e fêmeas, constituem-se em uma fração muito pequena dos animais.

Quando computada no presente estudo a morbidade proporcional, considerando o número total de mortes em relação ao número total de indivíduos da respectiva categoria animal, esta foi muito próxima entre novilhas, garrotes e vacas. Desta forma, os dados de morbidade inferidos apenas em relação ao total de doentes podem levar à distorção da realidade, quando os autores supracitados sugerem tratar-se de doença mais relacionadas às vacas.

A taxa de letalidade aqui encontrada foi semelhante à descrita anteriormente, estando em grande parte relacionada aos cuidados médico-veterinários que se presta aos animais acometidos. As taxas de morbidade e, conseqüentemente, mortalidade, foram bem menores que as indicadas por Ortolani ${ }^{5}$ (1993) e próximas as descritas por Lisbôa et al. ${ }^{21}$ (1996), de 3,2\%.

Foi levantado que a suplementação mineral era realizada de forma insatisfatória em boa parte das fazendas. A maioria utilizava misturas preparadas na propriedade $(57 \%)$ e muitas delas apresentaram, ao levan- 
tamento epidemiológico, ingestão insuficiente dos suplementos. No entanto, diferentemente de Ortolani ${ }^{5}$ (1993) e Lisbôa, et al. ${ }^{21}$ (1996) nenhuma fazenda empregava apenas cloreto de sódio e $9 \%$ delas utilizava sal com proteínas.

Em relação ao manejo sanitário, viu-se situação semelhante à relatadas por Ortolani ${ }^{5}(1993)$ e Lisbôa, et al. ${ }^{21}$ (1996), destacando-se apenas a baixa porcentagem de utilização de vacina contra brucelose.

Quanto à época de ocorrência dos surtos, estes apresentaram uma distribuição uniforme dentro do ano, contrastando com a ocorrência estacional, coincidindo com o início das chuvas, verificadas por Pinheiro, et al. ${ }^{9}$ (1984), Ortolani ${ }^{5}$ (1993) e Lisbôa, et al. ${ }^{21}$ (1996).Esta variação, talvez seja decorrente de particularidades climáticas nos anos de estudo, diferenças relativas ao tipo de exploração zootécnica ou particularidades da "Doença da Vaca Caída” dentro de suas possíveis causas etiológicas.

No estudo clínico dos animais atendidos, verificou-se que estes apresentam-se, via de regra, com manutenção da consciência ou apatia secundária ao comprometimento sistêmico, paraparesia ou tetraparesia flácidas, manutenção da função sensitiva, capacidades visual e auditiva, em boa parte dos casos paralisia flácida de cauda e em alguns diminuição do tônus lingual. Nenhuma destas características, no entanto, apresentou associação positiva à detecção de toxina botulínica ( $\mathrm{p}>0,05)$. A exploração destes sinais é de fundamental importância, entretanto, para o diagnóstico diferencial com neuropatias diversas.

O exame citológico do líquido cefalorraquidiano revelou contagem de células médias elevada, sendo as demais variavéis consideradas normais para a espécie bovina. Lisbôa, et al. ${ }^{8}$ (1996) não verificaram nenhuma anormalidade nos constituíntes do líquor de bovinos acometidos pela síndrome da vaca caída. A observação do desvio padrão e do coeficiente de variação desta variável demonstra grande variabilidade dos dados indicando disparidade de valores dentro da amostra. A observação da mediana, com valor de 11,5 células mononucleares por $\mathrm{mm}^{3}$, confirma que o aumento de celularidade restringiu-se a apenas alguns animais estudados.
Os exames necroscópicos e histopatológicos revelaram que $47,8 \%$ dos bovinos não apresentaram alterações dignas de nota e $35 \%$ enterite catarrohemorrágica, sendo este o achado necroscópico mais freqüente. Alguns bovinos apresentaram alterações de graus moderado a leve em rins, fígado e pulmões. As alterações pulmonares presentes decorreram, provavelmente, do decúbito prolongado e da aspiração de refluxo rumenal.

A positividade para toxina botulínica, de $41,4 \%$, foi próxima ao encontrado por Lisbôa, et al. ${ }^{21}$ (1996) na prova biológica e maior que a reportada por $\mathrm{Pi}$ nheiro, et al. ${ }^{9}$ (1984). Os primeiros discutem que a técnica de bioensaio em camundongos é pouco sensível e que com a microfixação de complemento obtiveram $92,9 \%$ de positivos. Almeida, et al. ${ }^{13}$ (1997), no entanto, reportam que a microfixação de complemento apresenta apenas $57 \%$ de especificidade, sendo nestas condições aceitável o contra argumento de que foram incluídos como positivos bovinos que na verdade não apresentavam-se intoxicados pela toxina botulínica (falso positivos).

Na presente pesquisa houve $38,1 \%$ de animais para os quais não se chegou a um diagnóstico etiológico definitivo, pois foram negativos para botulismo, apresentaram parâmetros hematológicos, de líqüor e anátomopatológicos normais e/ou com alterações inespecíficas, típicas do que vêm sendo descrito nos relatos sobre esta síndrome. Estes animais talvez possam ser incluídos numa forma idiopática da doença, até que novos e mais aprofundados estudos venham a classificar e determinar em definitivo sua etiologia e patogenia. Acreditamos ser esta classificação mais correta cientificamente, considerando, inclusive, o alerta de Baldassi ${ }^{22}$ (1986) sobre a necessidade da detecção laboratorial da toxina botulínica. Pressupor para este grupo de animais intoxicação botulínica não detectada seria descartar, precipitadamente, outras possíveis etiologias, como a toxina produzida pela flora rumenal descrita por Domingues-Bello et al. ${ }^{10}$ (1993).

Esta abordagem etiológica tem a vantagem de ressaltar a ocorrência de outras entidades mórbidas, de difícil diagnóstico clínico e laboratorial, principalmente a campo e sem um acurado exame necroscópico, 
histopatológico e toxicológico, que muitas vezes somamse incorretamente aos números da "mortalidade bovina por botulismo". Da mesma forma permite o estabelecimento de horizontes claros na investigação etiológica da doença, que tem, talvez, na raiz de sua controvérsia científica um problema importante em relação à dificuldade de diagnóstico.

\section{Conclusões}

Conclui-se que se trata de doença de etiologia multifatorial, que acomete a maioria das categorias de bovinos de corte e cujo panorama epidemiológico necessita de investigações mais abrangentes, a fim de se estabelecer métodos de controle mais eficientes.

\section{Abstract}

Objective: To investigate etiology and epidemiological scenario of the "bovine paraplegic disease" in bovines served at the Hospital Veterinário "Governador Laudo Natel" (Veterinarian Hospital "Governor Laudo Natel") of "Faculdade de Ciências Agrárias e Veterinárias da Universidade do Estadual Paulista" (College of Agrarian and Veterinary Sciences of the Paulista State University) (FCAV/UNESP), Campus of Jaboticabal, Jaboticabal, SP, Brazil. Material and Method: Clinical examination, neurological assessment, collection of blood serum and rumen liquid were carried out for detection of botulinal toxin, cephalorhachidian for the diagnosis of encephalitis, necroscopic test, histopathologic brain test and rabies diagnosis. Handling, type of zootechnical exploitation, nutrition and sanity were characterized, and epidemiological data of bouts were collected. Twentyfour (24) farms and twenty-nine (29) animals were included. Results: Epidemiological inquiry came to a total of 7.261 bovines, 143 sick generating a general morbidity rate of $2 \%$ (2.6\% amongst heifers; $2.2 \%$ amongst cows, $1.7 \%$ among bullocks and $0.6 \%$ among bulls), $40 \%$ of animals infected were bullocks, followed by cows $(28 \%)$ and heifers (27\%). Morbidity rate varied among properties $(0.14 \%$ to $57.5 \%)$ with deadliness close to $100 \%$. It was used regular salt mixed with mineral salt to $57 \%$ ) of properties and $30 \%$ of these to whole commercial mineral salt, amount supplied was considered as being inadequate in 54\%. Braquiaria sp predominated in extensive handling without manuring. Only two farmers accused osteophagia, despite the fact that $45 \%$ of pastures presented bones. Bovines appeared in extern-abdominal or lateral decubitus, $40 \%$ with decrease of tongue tonus and $80 \%$ with decrease of tonus and lack of tail movements. Among the diagnosis that could be confirmed, the following frequencies of occurrence were verified: $3.4 \%$ de polioencephalomalacea; $3.4 \%$ rabies; $10.3 \%$ encephalitis; $3.4 \%$ of organs failure; $41.4 \%$ botulism; $38.1 \%$ idiopathic, as animals have not presented signs or alterations that allowed a conclusive diagnosis. Conclusions: Conclusion was that it was a multifactor etiological disease that attacks most beef cattle categories and whose epidemiological scenario needs further investigations to determine more efficient control methods.

Keywords: Botulism. Clostridium botulinum. Bacterial toxins. Paraplegia, epidemiology. Paraplegia, etiology. Pasture. Brachiaria. Beef cattle. 


\section{Resumen}

Objetivo: Investigar la etiología y el panorama epidemiológico de la "enfermedad de la vaca caída" en ganado atendido en el Hospital Veterinario "Governador Laudo Natel" de la Facultad de Ciencias Agrarias y Veterinarias de la Universidad Estadual Paulista (FCAV/UNESP), Campus de Jaboticabal, Jaboticabal, SP, Brasil. Material y Método: Se realizó: examen clínico, evaluación neurológica, recogida de suero sanguíneo y líquido ruminal para la detección de toxina botulínica, líquido cefalorraquídeo para diagnóstico de encefalitis, examen necroscópico, examen histopatológico del cerebro y el diagnóstico de rabia. Se caracterizó el manejo, tipo de exploración zootécnica, nutrición, sanidad y se recogieron datos epidemiológicos de los brotes (irrupciones). Se incluyeron 24 fincas y 29 animales. Resultados: La investigación epidemiológica se hizo sobre un total de 7.261 animales, de los cuales 143 enfermos originando una tasa de morbilidad general del $2 \%$ (2,6\% entre las novillas, 2,2\% entre las vacas, $1,7 \%$ entre los becerros y 0,6\% entre los toros), $40 \%$ de los animales acometidos fueron becerros, seguidos por las vacas (28\%) y las novillas (27\%). La tasa de morbilidad tuvo una variación entre propiedades $(0,14 \%$ a 57,5\%) con letalidad cercana al $100 \%$. Usaban la sal común mezclada a la sal mineral, el 57\% de las propiedades y el 30\% de ellas, sal mineral comercial completa, la cantidad suministrada fue considerada inadecuada en 54\%. Predominaron pastos de Braquiaria sp en manejo extensivo sin abonos (fertilizantes). Solamente dos de los propietarios ser refirieron a osteofagia, aunque el $45 \%$ de los pastos presentaban osamenta. El ganado se presentó en decúbito abdominal externo o lateral, el $40 \%$ con disminución del tonos de la lengua y el $80 \%$ con disminución del tonos y ausencia de movimientos en la cola. Entre los diagnósticos que se pudieron confirmar se verificaron las frecuencias de ocurrencias como sigue: $3,4 \%$ de polioencefalomalacia; $3,4 \%$ de rabia; $10,3 \%$ de encefalitis; $3,4 \%$ de falencia de los órganos; 41,4\% de botulismo; 38,1\% idiopáticos, una vez que los animales no presentaban señales o alteraciones que permitieran un diagnóstico conclusivo. Conclusiones: Se concluye que se trata de una enfermedad de etiología multifactorial, que acomete la mayoría de las categorías del ganado de corte y cuyo panorama epidemiológico necesita de investigaciones más amplias, para establecer métodos de control más eficientes.

Palabras-clave: Botulismo. Clostridium botulinum. Toxina botulínica tipo A. Paraplejia, epidemiología. Paraplejia, etiología. Pastizales. Brachiaria. Ganado de corte

\section{Referências}

1. LISBÔA, J. A. N. Estudo epidemiológico, clínico e laboratorial da mortalidade de vacas nelore $\mathrm{e}$ suas mestiças, precedida pelo decúbito permanente, em municípios próximos à Botucatu, Estado de São Paulo. 1994. 79 f. Dissertação (Mestrado)Faculdade de Medicina Veterinária e Zootecnia da Universidade Estadual Paulista, Botucatu, 1994.

2. DUTRA, I. S. Botulismo em bovinos: doença da vaca caída. Jaboticabal: FUNEP, 1991.

3. OLIVEIRA, J. O. A síndrome da subnutrição. Lavoura, v. 96, n. 604, p.10-17, 1993.
4. LEMOS, P. B. et al. Mortalidade bovina. Revista dos Criadores, n. 127, p. 20-22, 1989.

5. ORTOLANI, E. L. Panorama epidemiológico da mortalidade enzoótica de bovinos adultos no Brasil e no Paraguai: Retrospectiva e levantamentos. Hora Veterinária, v. 12, p. 20-25, 1993.

6. TOKARNIA, C. H. et al. Situação atual e perspectivas da investigação sobre nutrição mineral em bovinos no Brasil. Pesquisa Veterinária Brasileira, v. 8, p. 1-16, 1988. 
7. DUTRA, I. S., DOBEREINER, J. Fatos e teorias sobre a "doença da vaca caída": botulismo. Hora Veterinária, v. 14, p. 7-10, 1995.

8. LISBÔA, J. A. N. et al. Resultados de patologia clínica e dosagens de elementos minerais em bovinos acometidos pelo botulismo epizoótico no Estado de São Paulo. Pesquisa Veterinária Brasileira, v. 16, p. 91-97, 1996.

9. PINHEIRO, H. H. et al. Incidência de botulismo em bovinos no Estado de Goiás. Hora Veterinária, v. 3 , p. $5-8,1984$.

10. DOMINGUEZ-BELLO, M. G. et al. Characterization of ruminal bacteria producing a toxin associated with a bovine paraplegic syndrome. Toxicon, v. 31, p. 1595-600, 1993.

11. SEVCIK, C. et al. Toxicology of a bovine paraplegic syndrome. Toxicon, v. 31, p. 1581-1594, 1993.

12. DUTRA, I. S. et al. Diagnóstico do botulismo em bovinos no Brasil pela técnica de microfixação de complemento. Pesquisa Veterinária Brasileira, v. 13, p. $83-86,1993$.

13. ALMEIDA, A. C.; ABREU, V. L. V.; LOBATO, F. C. F. Sensibilidade e especificidade do teste de microfixação de complemento com aquecimento em relação à soroneutralização em camundongos para diagnóstico do botulismo bovino. Arquivo Brasileiro de Medicina Veterinária e Zootecnia, v. 49, p.151-157, 1997.

14. BARROS FILHO, I. R. et al. Alguns aspectos sobre a mortalidade de bovinos no Estado de São Paulo. In: CONFERÊNCIA ANUAL DA SOCIEDADE PAULISTA DE MEDICINA VETERINÁRIA, 48., 1992, São Paulo. Anais... São Paulo, Sociedade Paulista de Medicina Veterinária, 1992. p. 23.
15. DOBEREINER, J. et al. Botulismo epizoótico dos bovinos no Brasil. In: CONGRESSO MUNDIAL DE BUIATRIA,16., 1990, Salvador. Anais... [s. n.]. p. 540-546.

16. REAL, C. M., REAL, M. R. Etiologia da mortandade de vacas em Mato Grosso do Sul, Brasil. Hora Veterinária, v.10, p. 39-53, 1991.

17. ROSENBERGER, G. et al. Exame clínico dos bovinos. 2. ed. Rio de Janeiro: Guanabara Koogan, 1983. p. 413-414.

18. CENTERS FOR DISEASE CONTROL AND PREVENTION. Botulism. Atlanta: CDC, 1990.

19. STATISTICAL ANALYSIS SYSTEM INSTITUTE. Statistical analysis system user's guide. version 6.11. Cary: SAS Institute, 1996.

20. LANGENEGGER, J., DOBEREINER, J. Fatores presdisponentes dos surtos de botulismo no cerrado de Goiás. In: CONGRESSO BRASILEIRO DE MEDICINA VETERINÁRIA, 17., 1980, Fortaleza. Resumos... [s.n.]. p. 17.

21. LISBÔA, J. A. N. et al. Epidemiologia e quadro clínico do botulismo epizoótico dos bovinos no Estado de São Paulo. Pesquisa Veterinária Brasileira, v. 16, p.67-74, 1996.

22. BALDASSI, L. Isolamento de bactérias do gênero Clostridium e detecção de toxina botulínica a partir de materiais obtidos de bovinos com suspeita clínica de botulismo. 1986. 58 f. Dissertação (Mestrado)-Faculdade de Saúde Pública da Universidade de São Paulo, São Paulo, 1986. 